\title{
Theoretical Description for Copper (II) Electrochemical Determination and Retention on a 1(2-pyridilazo)-2- naphthole-Modified Anode
}

\author{
Volodymyr V. Tkach ${ }^{1,2, *(\mathbb{D})}$, Marta V. Kushnir ${ }^{1(\mathbb{D})}$, Sílvio C. de Oliveira ${ }^{2(\mathbb{D})}$, Yana G. Ivanushko ${ }^{3(\mathbb{D})}$, \\ Viktoria O. Tkach ${ }^{4 \mathbb{D}}$, Hanna Ya. Mytrofanova ${ }^{4 \mathbb{D}}$, Anatolii O. Zadoia ${ }^{4} \mathbb{D}^{\mathbb{D}}$, Petro I. Yagodynets ${ }^{1, * \mathbb{D}}$, \\ Zholt O. Kormosh ${ }^{5(\mathbb{D})}$, Olga V. Luganska ${ }^{6(\mathbb{D})}$, Galyna M. Pochenchuk ${ }^{1(\mathbb{D})}$

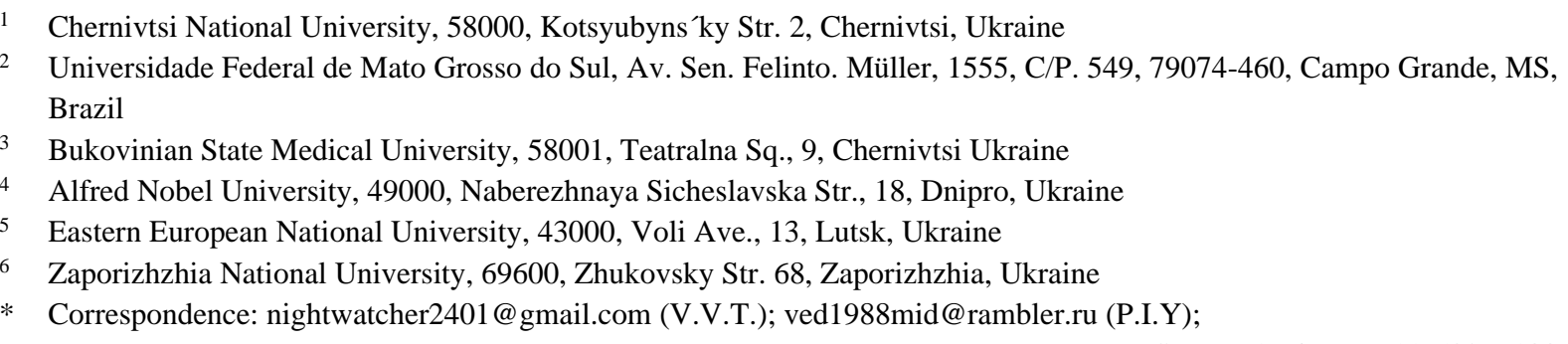

Scopus Author ID 55758299100

Received: 15.09.2020; Revised: 14.10.2020; Accepted: 16.10.2020; Published: 17.10.2020

\begin{abstract}
A modern and flexible spectrophotometric method for copper determination in food has been proposed to be posted on the electrochemical tracks. The theoretical analysis of the correspondent model confirms the efficiency of the electrochemical reaction for either electroanalytical or electro-synthetical or eliminative processes for copper. As for the oscillatory instability, it will be caused by either chemical or electrochemical influences on the double electric layer.
\end{abstract}

Keywords: copper ion; electrochemical sensor; complexation; 1(2-pyridilazo)-2-naphthol; stable steady-state.

(C) 2020 by the authors. This article is an open-access article distributed under the terms and conditions of the Creative Commons Attribution (CC BY) license (https://creativecommons.org/licenses/by/4.0/).

\section{Introduction}

Copper is one of the most used metals [1-4]. It is one of the first metals known to humanity, and it is very important either for the biological functions or for the industry. For example, hemocyanin, a blue blood pigment of mollusks, and some crustacea contain bivalent copper ion in its center. Also, copper is frequently used in motherboard production, the reason why the wastewater of the computing industry is highly polluted by $\mathrm{Cu}^{2+}$.

In excess, these ions are highly toxic [5-7]. They may even appear in food [8-12] and beverages stored in the copper vessels. Its biological action is dose-related. Therefore, the development of both determination and elimination (recovery) of copper ions from food, beverage, and wastewater is really actual.

In work [12], a spectrophotometric method for copper determination in Brazilian tequila (cachaça) beverage has been developed. It was based on $\mathrm{Cu}$ (II) complexation with Sudan I [13] analog 1-(2-pyridilazo)-2-naphthol (Fig. 1) 


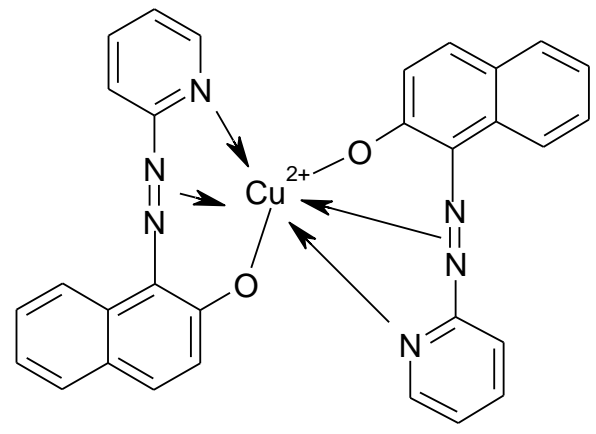

Figure 1. Copper complex with 1(2-pyridilazo)-2-naphthol.

This method may be easily re-confected as electrochemical, as the analogous methods for copper and other metal determinations [14-15] have already been known. The electrochemical stage would lead to complex compound electropolymerization.

As both electro-analytical and electro-synthetical processes involving conducting polymers tend to be accompanied by electrochemical instabilities [16-21], influencing the behavior of the electroanalytical process, it is necessary to verify their probability to occur by a theoretical a priori analysis, also permitting the theoretical comparison of the electroanalytical system with the similar ones.

Therefore, in this work, the process with copper electrochemical determination and retention by complexation with 1-(2-pyridilazo)-2-naphthol is theoretically evaluated by the development and analysis of the correspondent mathematical model.

\section{Materials and Methods}

In this system, the ligand 1(2-pyridilazo)-2-naphthol, highly insoluble in water, is deposited over the anodic surface. Therefore, copper ions will diffuse towards the pre-surface layer and react with the ligand, forming a complex. The complex ion will be, therefore, polymerized (Fig. 2).

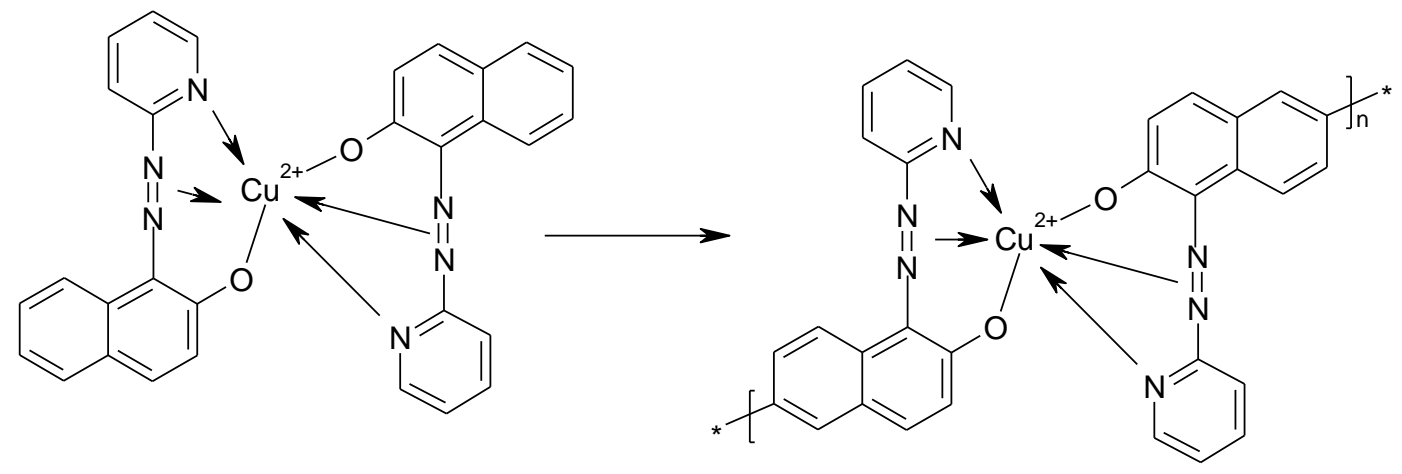

Figure 2. Copper complex electropolymerization.

As the metal ion is considered a donating fragment, the complex polymerization potential will be lower than that for the proper ligand. Also, the complex structure may permit more than one electropolymerization scenarios, including (rarely) the pyridinic nuclei fragments involvement in the electropolymerization process.

Therefore, in order to describe the electrochemical behavior of copper electrochemical determination by complexation with 1(2-pyridilazo)-2-naphthol, we introduce three variables: $\mathrm{c}$ - copper ions concentration in the pre-surface layer;

$\mathrm{m}$ - complex monomer surface coverage degree. 
In order to simplify the modeling, we assume that:

- the background electrolyte is taken in excess so that we can neglect the migration flow and the oxidizing dopant oxidation change;

- the reactor is intensively stirred so that we may neglect the convection flow;

- the pre-surface layer concentration profile is linear, and its thickness is constant, equal to $\delta$.

It is possible to prove that the differential equations' set describing the system may be described as:

$$
\left\{\begin{array}{l}
\frac{d c}{d t}=\frac{2}{\delta}\left(\frac{\Delta}{\delta}\left(c_{0}-c\right)-r_{C}\right) \\
\frac{d m}{d t}=\frac{1}{M}\left(r_{C}-r_{p 1}-r_{p 2}\right)
\end{array}\right.
$$

Herein, $\Delta$ is the diffusion coefficient, $\mathrm{c}_{0}$ is the copper ions bulk concentration, $\mathrm{M}$ is the complex compound maximal surface concentration, and the parameters $r$ are the correspondent reaction rates, calculated as $(2-4)$ :

$$
\begin{aligned}
& r_{C}=k_{C} c(1-m)^{2} \exp (a m) \\
& r_{p 1}=k_{p 1} m^{x} \exp \left(\frac{(x-2) F \varphi_{0}}{R T}\right) \\
& r_{p 2}=k_{p 2} m^{y} \exp \left(\frac{(y-2) F \varphi_{0}}{R T}\right)
\end{aligned}
$$

Herein, the parameters $\mathrm{k}$ are the correspondent reaction rate constants, $\mathrm{x}$ and $\mathrm{y}$ are polymer chain lengths, $a$ is the parameter relating the double electric layer (DEL) capacitance with the complex formation, $\mathrm{F}$ is the Faraday number, $\varphi_{0}$ is the potential slope in DEL, related to the zero-charge potential, $\mathrm{R}$ is the universal gas constant, and $\mathrm{T}$ is the absolute temperature of the solution.

Taking into account that the electropolymerization of the complex compound is realized by two parallel scenarios like also the DEL influences on the chemical stages, the behavior of the electro-analytical system is dynamic. Nevertheless, it is efficient from both electroanalytical and electro-synthetical points of view, as shown below.

\section{Results and Discussion}

In order to describe the system with the copper electrochemical detection or retention by the complexation with 1-(2-pyridilazo)-2-naphthol, we analyze the equation-set (1) and the algebraic relations $(2-4)$ by means of linear stability theory. The Jacobian functional matrix steady-state elements for this system will be described as:

$$
\left(\begin{array}{ll}
a_{11} & a_{12} \\
a_{21} & a_{22}
\end{array}\right)
$$

in which:

$$
\begin{gathered}
a_{11}=\frac{2}{\delta}\left(\frac{\Delta}{\delta}\left(c_{0}-c\right)-k_{C}(1-m)^{2} \exp (a m)\right) \\
a_{12}=\frac{2}{\delta}\left(2 k_{C} c(1-m) \exp (a m)-a k_{C} c(1-m)^{2} \exp (a m)\right) \\
a_{21}=\frac{1}{M}\left(k_{C}(1-m)^{2} \exp (a m)\right) \\
a_{22}=\frac{1}{M}\left(-2 k_{C} c(1-m) \exp (a m)+a k_{C} c(1-m)^{2} \exp (a m)-\right. \\
x k_{p 1} m^{x-1} \exp \left(\frac{(x-2) F \varphi_{0}}{R T}\right)-j k_{p 1} m^{x} \exp \left(\frac{(x-2) F \varphi_{0}}{R T}\right)-y k_{p 2} m^{y-1} \exp \left(\frac{(y-2) F \varphi_{0}}{R T}\right)- \\
\left.j k_{p 2} m^{y} \exp \left(\frac{(y-2) F \varphi_{0}}{R T}\right)\right)(9)
\end{gathered}
$$

The principal conditions for the system singular points are exposed toTable 1: 
Table 1. The bivariant systems' main singular point requirements.

\begin{tabular}{l|l} 
Steady-state stability & $\operatorname{Tr} \mathrm{J}<0$, Det $\mathrm{J}>0$ \\
\hline Oscillatory instability (Hopf bifurcation) & $\operatorname{Tr} \mathrm{J}=0$, Det $\mathrm{J}>0$ \\
\hline Monotonic instability (saddle-node or static bifurcation) & $\operatorname{Tr} \mathrm{J}<0$, Det $\mathrm{J}=0$
\end{tabular}

In order to avoid the cumbersome expressions, we expose the Jacobian determinant as:

$$
\frac{2}{\delta M}\left|\begin{array}{cc}
-\kappa-\Lambda & \Phi \\
\Lambda & -\Phi-\Omega-X
\end{array}\right|
$$

Taking into account the elements (5) and (8), the oscillatory behavior is capable of appearing in this system. The main Hopf bifurcation condition is realized if the main diagonal contains positive elements related to the positive callback.

In this system, there are three elements, capable of being positive, and, consequently, to be responsible for the oscillatory behavior via Hopf bifurcation, against one or two in the similar systems [20 - 21], due to the possibility of more than one electropolymerization scenarios. Besides of the member $a k_{C} c(1-m)^{2} \exp (a m)>0$ if a $>0$, describing the DEL rearrangement due to the copper ion inclusion into a complex compound, two elements $-j k_{p 1} m^{x} \exp \left(\frac{(x-2) F \varphi_{0}}{R T}\right)$ and $-j k_{p 2} m^{y} \exp \left(\frac{(y-2) F \varphi_{0}}{R T}\right)$, positive if $\mathrm{j}<0$, typical to the similar systems, related to the DEL influence of the electrochemical stage, is also responsible for the oscillatory behavior.

The electrochemical oscillations amplitude and frequency will be highly dependent on the content of the background electrolyte. Their realization is expected to the concentration values beyond the detection limit. Mathematically, this condition will be exposed as:

$$
\left\{\begin{array}{c}
-\frac{2}{\delta}(\kappa+\Lambda)-\frac{1}{M}(\Phi+\Omega+X)=0 \\
\frac{2}{\delta M}(\kappa \Phi+\kappa \Omega+\kappa X+\Lambda \Omega+\Lambda X)>0
\end{array}\right.
$$

Yet, if the mentioned elements are negative, the steady-state stability will be obtained. Really. Opening the brackets and applying the stability requisite, we obtain the steady-state stability requisite exposed as:

$$
\left\{\begin{array}{c}
-\frac{2}{\delta}(\kappa+\Lambda)-\frac{1}{M}(\Phi+\Omega+X)<0 \\
\frac{2}{\delta M}(\kappa \Phi+\kappa \Omega+\kappa X+\Lambda \Omega+\Lambda X)>0
\end{array}\right.
$$

This requisite describes that the electrochemical system will be efficient for both the determination and recapture of divalent copper ions. Moreover, it will be either diffusion or kinetically controlled. This condition is satisfied in a relatively vast parameter region, in which the dependence between the electrode current and copper concentration will be linear.

The monotonic instability, correspondent to the detection limit, separates the steady stable-states from unstable states. Its condition is mathematically exposed as (13):

$$
\left\{\begin{array}{c}
-\frac{2}{\delta}(\kappa+\Lambda)-\frac{1}{M}(\Phi+\Omega+X)<0 \\
\frac{2}{\delta M}(\kappa \Phi+\kappa \Omega+\kappa X+\Lambda \Omega+\Lambda X)=0
\end{array}\right.
$$

In order to use this process for copper elimination from food, beverages, and wastewater, it is suitable to mount an electrochemical set as in Fig. 3: 


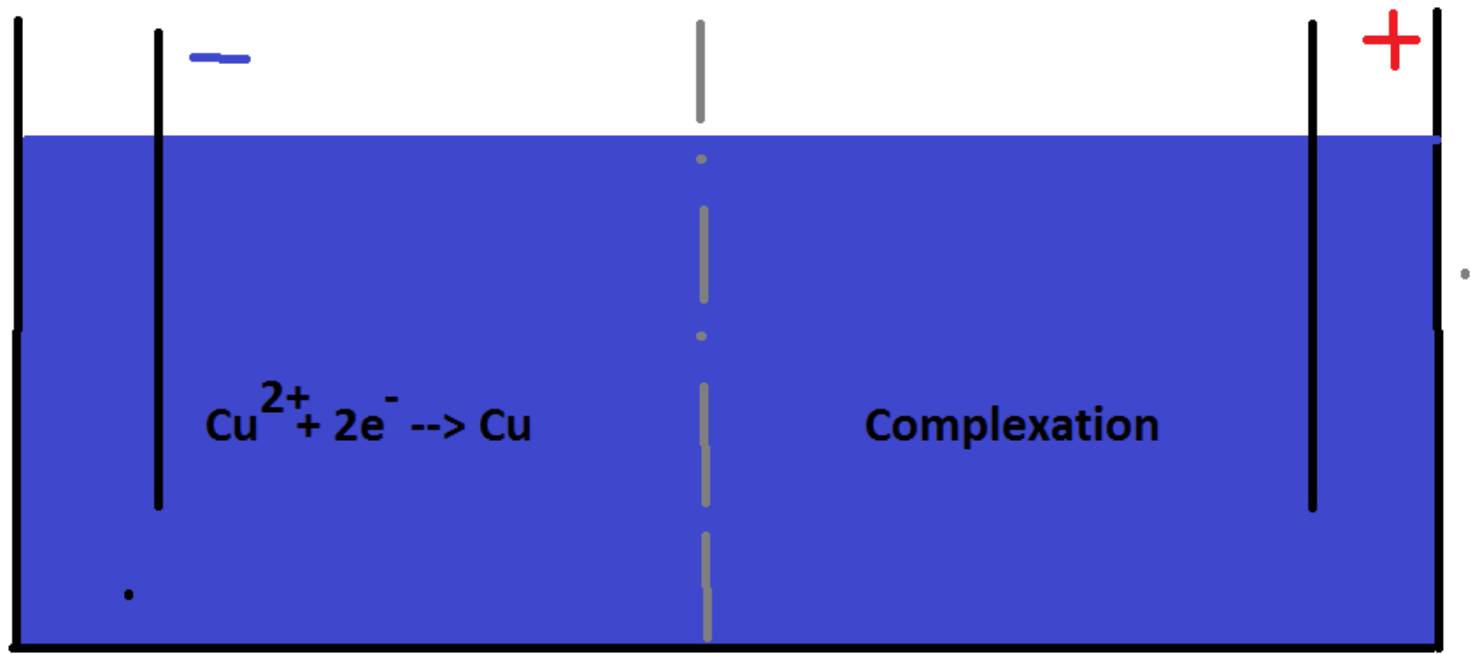

\section{PVP membrane}

Figure 3. The scheme for the copper (II) cathodic and simultaneous anodic elimination.

In this case, the cathodic electrolyte, containing bivalent copper halogenides, undergoes the electrochemical reduction, yielding the metallic copper. On the right side, copper is recuperated by a complex-forming process, exposed above. This lets us combine two electrochemical processes for copper recycling in only one, minimizing the energy expense and copper loss.

As the bivalent copper is present in the wastewater in the form of halogenides, it is necessary to avoid the toxic chlorine evolution:

$$
2 \mathrm{Cl}^{-}-2 \mathrm{e}^{-} \rightarrow \mathrm{Cl}_{2}
$$

Therefore, a membrane impeding the chalcogenide ions to trespass towards the anodic electrolyte is necessary to maintain the process safely. The cathodic copper recovery produces a metal coating. The anodic copper recovery, an interesting conducting polymer of complex compounds.

If the copper electrolyte contains the single salt of copper, there is a possibility to determinate both cation and anion concentration by electropolymerization peak, as the conducting polymer is doped during the electrochemical polymerization of its monomer. In this case, a trivariate system has to be used in order to describe the behavior of this system.

\section{Conclusions}

From the theoretical model evaluation of copper detection and retention by complexformation with 1-(2-pyridilazo)-2-naphthol, it has been possible to conclude that it is an efficient electro-analytical and electro-synthetical, capable also of diminishing the copper loss in wastewater. The copper is efficiently recovered by complex-formation with the further polymerization of the complex. For its turn, the oscillatory behavior is expected to be probable due to the double electric layer structure changes during the process on both of the stages. The probability of the oscillatory behavior and the oscillation amplitude will be highly dependent on the solution background electrolyte composition.

\section{Funding}

This research received no external funding. 


\section{Acknowledgments}

This research has no acknowledgment.

\section{Conflicts of Interest}

The authors declare no conflict of interest.

\section{References}

1. Li, X.; Wang, Y.; Yin, C.; Yin, Z. Copper nanowires in recent electronic applications: progress and perspectives. Journal of Materials Chemistry C 2020, 8, 849-872, https://doi.org/10.1039/C9TC04744A.

2. Lee, H.; Wu, X.; Sun, L. Copper-based homogeneous and heterogeneous catalysts for electrochemical water oxidation. Nanoscale 2020, 12, 4187-4218, https://doi.org/10.1039/C9NR10437B.

3. Al-Hakkani, M. Biogenic Copper Nanoparticles and Their Applications: A Review.SN Appl. Sci.2020, 2,https://doi.org/10.1007/s42452-020-2279-1.

4. Kaminwar, N.S.; Tekale, S.U.; Chidrawar, A.B.; Kotai, L.; Pawar, R.P.Eco-Friendly Synthesis of 1,4Dihydropyrano-[2,3-c]pyrazoles Using Copper Nanoparticles Grafted on Carbon Microsphere as a Heterogeneous Catalyst.Lett. Appl. NanoBioSci.2020, 9, 1521-1528.

5. Cortes, A.A.; Zuñiga, J.M. The use of copper to help prevent transmission of SARS-Coronavirus and Influenza viruses. A general Review. Diagnostic Microbiology and Infectious Disease 2020, https://doi.org/10.1016/j.diagmicrobio.2020.115176

6. Taylor, A.A.; Tsuji, J.S.; Garry, M.R.; McArdle, M.E.; Goodfellow, W.L.; Adams, W.J.; Menzie, C.A. Critical Review of Exposure and Effects: Implications for Setting Regulatory Health Criteria for Ingested Copper. Environmental Management 2020, 65, 131-159,https://doi.org/10.1007/s00267-019-01234-y.

7. Lopez, J.S.; Lee, L.; Mackey, K.R.M. The Toxicity of Copper to Crocosphaera watsonii and Other Marine Phytoplankton: A Systematic Review.Mar. Biogeochem.2019, 5,https://doi.org/10.3389/fmars.2018.00511.

8. Kontoudakis, N.; Smith, M.; Smith, P.A.; Wilkes, E.N.; Clark, A.C. The colorimetric determination of copper in wine: total copper. Australian Journal of Grape and Wine Research 2020, 26, 121-129, https://doi.org/10.1111/ajgw.12425.

9. Khoshmaram, L.; Saadati, M.; Karimi, A. A simple and rapid technique for the determination of copper based on air-assisted liquid-liquid microextraction and image colorimetric analysis. Analytical Methods 2020, 12, 3490-3498,https://doi.org/10.1039/D0AY00706D.

10. Alharthi, S.S.; Al-Saidi, H.M. Spectrophotometric Determination of Trace Concentrations of Copper in Waters Using the Chromogenic Reagent 4-Amino-3-Mercapto-6-[2-(2-Thienyl)Vinyl]-1,2,4-Triazin-5(4H)One: Synthesis, Characterization, and Analytical Applications. Applied Sciences 2020, 10,https://doi.org/10.3390/app10113895.

11. Rattanakit, P. Determination of copper(II) by pyrogallol red with sensitivity enhancement of cetyltrimethylammonium bromide in reverse flow injection spectrophotometric system. International Journal of Environmental Analytical Chemistry 2020,https://doi.org/10.1080/03067319.2020.1784411.

12. Oliveira, R.W.; Gomes, P.; Ribeiro, J.; Reis, J.; Fontenele, M.; Everton, G.; Lyra, W.; Louzeiro, H.; Paula, M.; Filho, V. Determinação espectrofotométrica de Cobre(II) em aguardente de mandioca (Tiquira). Revista Colombiana de Ciencias Químico-Farmacéuticas 2020, 49, 353-371, https://doi.org/10.15446/rcciquifa.v49n2.89507. (in Portuguese)

13. Tkach, V.; Kushnir, M.; de Oliveira, S.; Ivanushko, Y.; Velyka, А.; Молодяну, A.; Yagodynets, Р.; Kormosh, Z.; Reis, L.; Luganska, O.; Palamarek, K.; Bredikhina, Y. Electrochemical Determination of Sudan Dyes and Two Manner to Realize it: a Theoretical Investigation. Letters in Applied NanoBioScience 2020, $9,1451-1458$.

14. Bagheri, A.; Hassani Marand, M. Voltammetric and Potentiometric Determination of $\mathrm{Cu}^{2+}$, using an Overoxidized Polypyrrole Based Electrochemical Sensor.Russ. J. Electrochem.2020, 56, 453-461, https://doi.org/10.1134/S1023193520060026.

15. Jiang, W.-X.; Liu, W.-X.; Wang, C.-L.; Zhan, S.-Z.; Wu, S.-P. A bis(thiosemicarbazonato)-copper complex, a new catalyst for electro- and photo-reduction of $\mathrm{CO} 2$ to methanol. New Journal of Chemistry 2020, 44, 2721-2726, https://doi.org/10.1039/C9NJ05672F.

16. Das, I.; Goel, N.; Agrawal, N.R.; Gupta, S.K. Growth patterns of dendrimers and electric potential oscillations during electropolymerization of pyrrole using mono-and mixed surfactants. J. Phys. Chem. B 2010, 114, 12888-12896, https://doi.org/10.1021/jp105183q.

17. Das, I.; Goel, N.; Gupta, S.K.; Agrawal, N.R. Electropolymerization of pyrrole: Dendrimers, nano-sized patterns and oscillations in potential in presence of aromatic and aliphatic surfactants. J. Electroanal. Chem.2012, 670, 1-10, https://doi.org/10.1016/j.jelechem.2012.01.023. 
18. Tkach, V.V.; Kushnir, M.V.; Ivanushko, Y.G.; de Oliviera, S.The Theoretical Description for Neotame Electrochemical Determination, Assisted by Vanadium Oxyhydroxide Composite with a Squarainic Dye. Appl. J. Env. Eng. Sci. 2020, 6, 109-115.

19. Tkach, V.V.; Kushnir, M.V.; Storoshchuk, N.M.; Ivanushko, Y. The Theoretical Description for the Confection of the Novel Thiourea-Based Active Surface for Cathodic Conducting Polymer Deposition. Appl. J. Env. Eng. Sci.2020, 6, 143-148.

20. Tkach, V.; Kushnir, M.; Ivanushko, Y.; de Oliveira, S.; Reis, L.; Yagodynets', P.; Kormosh, Z.The Theoretical Description for the Electrochemical Synthesis of Squaraine Dye Doped Conducting Polymer. Appl. J. Env. Eng. Sci. 2020, 6, 51-56.

21. Tkach, V.V.; Storoshchuk, N.M.; Romaniv, L.V.; De Oliveira, S.C.; Luganska, O.V.; Gala, H.B.; Tchikuala, E.F.; Yagodynets, P.I. The theoretical evaluation of the poly (3, 4'dimetylpyrrole) cathodic electrodeposition assisted by manganate ions. Vietnam J.Chem. 2018, 56, 440-444, https://doi.org/10.1002/vjch.201800027. 